\title{
Haplotype analysis of Norwegian and Swedish patients with acute intermittent porphyria (AIP): Extreme haplotype heterogeneity for the mutation R116W
}

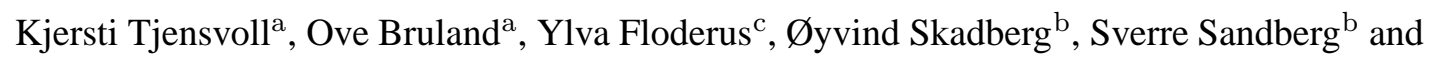 \\ Jaran Apold ${ }^{\mathrm{a}, *}$ \\ ${ }^{a}$ Center for Medical Genetics and Molecular Medicine, Haukeland University Hospital, N-5021 Bergen, Norway \\ ${ }^{\mathrm{b}}$ Norwegian Porphyria Centre, Laboratory of Clinical Biochemistry, Haukeland University Hospital, N-5021 \\ Bergen, Norway \\ ${ }^{\mathrm{c}}$ Porphyria Centre Sweden, CMMS C2-71, Huddinge University Hospital, SE-141 86 Stockholm, Sweden
}

\begin{abstract}
Acute intermittent porphyria (AIP), the most common of the acute porphyrias, is caused by mutations in the gene encoding hydroxymethylbilane synthase (HMBS) also called porphobilinogen deaminase (PBGD). The mutation spectrum in the HMBS gene is characterized by a majority of family specific mutations. Among the exceptions are R116W and W198X, with high prevalence in both the Dutch and Swedish populations. These two mutations were also detected in unrelated Norwegian patients. Thus, Norwegian and Swedish patients were haplotyped using closely linked flanking microsatellites and intragenic single nucleotide polymorphisms (SNPs) to see if the high frequency of these two mutations is due to a founder effect. Twelve intragenic SNPs were determined by a method based on fluorescent restriction enzyme fingerprinting single-strand conformation polymorphism (F-REF-SSCP).

W198X occurred exclusively on one haplotype in both Norwegian and Swedish patients, showing that it has originated from a common gene source. In contrast, R116W was found on three different haplotypes in three Norwegian families, and in five Swedish families on four or five haplotypes. This extreme haplotype heterogeneity indicates that R116W is a recurrent mutation, maybe explained by the high mutability of $\mathrm{CpG}$ dinucleotides. This can also explain why it is the only AIP mutation reported to occur in seven different populations (Norway, Sweden, Finland, Netherlands, France, Spain and South Africa).
\end{abstract}

Keywords: Acute intermittent porphyria, AIP, porphyria, SNP, microsatellites, haplotyping, genetic markers, HMBS, PBGD, V215E, L238P

Databases: "1996 Généthon Microsatellite Maps" database http://hdklab.wustl.edu/"genlink/genethon_frame/ The Human Gene Mutation Database (HGMD), Cardiff http://www.hgmd.org

\section{Introduction}

Acute intermittent porphyria (AIP) is an autosomal dominant disorder caused by mutations in hydrox-

*Corresponding author: Jaran Apold, Center for Medical Genetics and Molecular Medicine, University of Bergen, Haukeland University Hospital, N-5021 Bergen, Norway. Tel.: +47 559754 96; Fax: +47 559754 79; E-mail: Jaran.Apold@haukeland.no. ymethylbilane synthase (HMBS), the third enzyme of the heme biosynthetic pathway. AIP is the most common of the acute porphyrias and occurs in all ethnic groups [5]. The estimated prevalence of AIP in both Norway and Sweden is $1 / 10000$, while it in northern Sweden is $8 / 10000$ [6]. Mutations in this gene were first reported in 1989 [7,8], and to date 179 mutations are described [11]. The majority are nucleotide substitutions (missense/nonsense), but deletions/insertions 
and splicing defects are also reported.

Most of the HMBS mutations are family specific. In contrast two mutations, R116W and W198X, have been observed in several populations. W198X has earlier been described in several families in northern Sweden [13], one family in Finland [10] and one Norwegian family [19]. On the other hand, R116W has been reported in seven different populations. The highest frequency was noted in the Netherlands, where several unrelated Dutch AIP families were proven to have this mutation [9]. In addition, R116W has been reported in Sweden [14], Finland [10], France [9] Spain [20], South Africa [16-18], and in the Norwegian families here reported.

The HMBS gene was primarily screened for disease causing mutations in Norwegian AIP patients. However, the fact that both W198X and R116W occur in different populations prompted us to perform haplotype analysis to find the mutational history of these mutations. Three flanking microsatellite markers, spanning $\mathrm{a} \sim 2.9 \mathrm{cM}$ region (Fig. 1), were analyzed by standard procedure. In addition, the HMBS gene was screened for SNPs by a recently developed technology, fluorescent restriction enzyme fingerprinting single-strand conformation polymorphism (F-REF-SSCP) [2].

\section{Materials and methods}

\subsection{Subjects}

Mutation screening, by denaturing gradient gel electrophoresis (DGGE), was performed in 20 Norwegian families likely to have AIP based on clinical observations and biochemical analysis.

Normal haplotypes were determined from 31 healthy Norwegian individuals, and 13 healthy individuals from Swedish AIP families.

Mutant haplotype analysis was performed for the mutations W198X (eight families) and R116W (eight families).

\subsection{Mutation screening by $D G G E$}

Exon 1 and 3-15, with flanking intron sequences, were amplified by PCR $(50 \mu \mathrm{l})$ in the presence of $10 \times$ PCR buffer (Boehringer Mannheim, http://biochem.boehringer-mannheim.com/), $1.5 \mathrm{mM} \mathrm{MgCl}_{2}$, $0.4 \mu \mathrm{M}$ of each primers, $0.2 \mathrm{mM}$ of each dNTP, $1 \mathrm{U}$ Taq polymerase (Boehringer Mannheim) and $300 \mathrm{ng}$ genomic DNA. Selection of primers were as previously described by Nissen et al. 1997 [15]. PCR amplification was performed in a 9700 Thermal Cycler (Perkin Elmer, http://home.appliedbiosystems.com/) with the cycling parameters: $95^{\circ} \mathrm{C} 5 \mathrm{~min} ; 35$ cycles of $94^{\circ} \mathrm{C}$ $60 \mathrm{sec}$, annealing temperature ranging from $58-70^{\circ} \mathrm{C}$ $60 \mathrm{sec}, 72^{\circ} \mathrm{C} 90 \mathrm{sec} ; 72^{\circ} \mathrm{C} 10 \mathrm{~min} ; 99^{\circ} \mathrm{C} 7 \mathrm{~min} ; 65^{\circ} \mathrm{C}$ $60 \mathrm{~min} ; 37^{\circ} \mathrm{C} 60 \mathrm{~min} ; 4^{\circ} \mathrm{C}$ hold. DGGE was performed as described by Nissen et al. 1997 [15] with the following gel \% modifications: $40-80 \%$ (exon 1 ), $0-80 \%$ (exon 10), 30-75\% (exon 12 and 13) and 20-60\% (exon $15)$.

\subsection{F-REF-SSCP: Analysis of intragenic markers (SNPS)}

F-REF-SSCP was performed as described by Bruland et al., in manuscript [2].

\subsection{GeneScan: Analysis of flanking microsatellites markers}

The flanking microsatellites D11S924, D11S939 and D11S4104 (figure 1) were amplified by PCR (50 $\mu \mathrm{l})$ under the following conditions: $10 \times \mathrm{PCR}$ buffer (Perkin Elmer), $1.5 \mathrm{mM} \mathrm{MgCl}_{2}, 0.2 \mu \mathrm{M}$ of each primers, $0.1 \mathrm{mM}$ of each dNTP, 1U AmpliTaq polymerase (Perkin Elmer) and 300 ng genomic DNA. In addition $1 \mathrm{M}$ betaine was added to the D11S924 reaction mixture. PCR amplification was performed in a 9700 Thermal Cycler (Perkin Elmer) with the cycling parameters: $95^{\circ} \mathrm{C} 5 \mathrm{~min} ; 35$ cycles of $94^{\circ} \mathrm{C} 30 \mathrm{sec}$, $55^{\circ} \mathrm{C}(\mathrm{D} 11 \mathrm{~S} 939)$ and $52^{\circ} \mathrm{C}$ (D11S924 and D11S4104) $30 \mathrm{sec}, 72^{\circ} \mathrm{C} 1 \mathrm{~min} ; 72^{\circ} \mathrm{C} 7 \mathrm{~min} ; 4^{\circ} \mathrm{C}$ hold. The allele sizes, primer sequences and the percent heterozygosity for each microsatellite were obtained from the "1996 Généthon Microsatellite Maps" database (http://hdklab.wustl.edu/ genlink/genethon frame/).

$1 \mu \mathrm{l}$ PCR product was added to a mixture of $2 \mu \mathrm{l}$ Tamra-350 standard (Perkin Elmer) and $6 \times$ standard formamide loading buffer. The products were denatured for $5 \mathrm{~min}$ at $98^{\circ} \mathrm{C}$, and then separated on a $5 \%$ acrylamide-TBE ( $89 \mathrm{mM}$ Tris- $\mathrm{HCl}, 89 \mathrm{mM}$ boric acid, $2 \mathrm{mM}$ EDTA) gel at $51^{\circ} \mathrm{C}$ on ABI 377 .

\section{Results}

We screened 5539 bp (exon 3-15), 1372 bp coding and $4167 \mathrm{bp}$ non-coding sequence, in the HMBS gene for SNPs by F-REF-SSCP [2]. Specific regions with shifts were sequenced, and a total of 12 SNPs were de- 
Table 1

Intragenic SNPs in the HMBS gene found by F-REF-SSCP followed by sequencing

\begin{tabular}{|c|c|c|c|}
\hline Polymorphism & $\begin{array}{l}\text { Intragenic marker (SNP) } \\
\text { (allele 1: allele 2) }\end{array}$ & $\begin{array}{l}\text { Localization in } \\
\text { the HMBS gene }\end{array}$ & $\begin{array}{l}\text { Nucleotide number/ } \\
\text { Nucleotide variation }\end{array}$ \\
\hline SNP 1 & 53 bp : 54 bp & Intron 2 & $3119 \mathrm{G} / \mathrm{T}$ \\
\hline SNP 2 & $180 / 182$ bp : 184/185 bp & Intron 3 & $3581 \mathrm{G} / \mathrm{A}$ \\
\hline SNP 3 & $60 \mathrm{bp} \mathrm{:} 61 \mathrm{bp}$ & Intron 4 & $3982 \mathrm{~T} / \mathrm{C}$ \\
\hline SNP $4 * * *$ & 81 bp : Unknown & Intron 6 & 4589del8 \\
\hline SNP $5^{* * *}$ & 88 bp : Unknown & Intron 8 & $5099 \mathrm{G} / \mathrm{T}$ \\
\hline SNP $6^{*}$ & 101 bp : 111 bp & Intron 9 & $5481 \mathrm{C} / \mathrm{T}$ \\
\hline SNP $7 *$ & 34 bp : 36 bp & Intron 9 & $6324 \mathrm{C} / \mathrm{T}$ \\
\hline SNP $8^{*}$ & 301/303 bp : 303/307 bp & Exon 10 & $6479 \mathrm{G} / \mathrm{T}$ \\
\hline SNP 9* & $154 \mathrm{bp}: 157 \mathrm{bp}$ & Intron 10 & $7064 \mathrm{~A} / \mathrm{C}$ \\
\hline SNP $10^{*}$ & 218 bp : 226 bp & Intron 12 & $7539 \mathrm{C} / \mathrm{T}$ \\
\hline SNP $11^{*}$ & $207 \mathrm{bp} \mathrm{:} 259 \mathrm{bp}$ & Intron 13 & $7787 \mathrm{G} / \mathrm{A}$ \\
\hline SNP $12^{*}$ & 70 bp : 71 bp & Intron 14 & $7998 \mathrm{G} / \mathrm{A}$ \\
\hline
\end{tabular}

${ }^{*}$ The selection of informative SNPs, arbitrarily numbered, used to determine haplotypes.

** The nucleotide variations are numbered according to the genomic sequence of Yoo et al. [23] with A of the ATG initiation codon in exon 1 numbered +1 .

*** Since F-REF-SSCP is based on single-stranded DNA conformations, a pattern of 1-4 bands can be seen on the gel for the two alleles present. However, in some cases the appurtenant allele can be difficult to detect (SNP 4 and 5).

Table 2

Disease haplotypes linked to the mutations W198X and R116W in Norwegian and Swedish AIP families

\begin{tabular}{lcccccc}
\hline Mutation & Country & \multicolumn{3}{c}{ Locus } & Haplotype \\
\cline { 3 - 6 } & & $\begin{array}{c}\text { D11S939 } \\
\text { (bp) }\end{array}$ & $\begin{array}{c}\text { D11S4104 } \\
\text { (bp) }\end{array}$ & $\begin{array}{c}\text { D11S924 } \\
\text { (bp) }\end{array}$ & Intragenic markers $^{\mathrm{a}}$ & \\
\hline W198X & Norway & 240 & 188 & 246 & $\mathrm{M}_{1}$ & $\mathrm{I}$ \\
R116W & Norway & 240 & 188 & 248 & $\mathrm{M}_{4}$ & II \\
& & 248 & 194 & 250 & $\mathrm{M}_{2}$ & III \\
& & 240 or 246 & 196 & 248 & $\mathrm{M}_{3}$ & IV \\
W198X & Sweden & 240 & 188 & 246 & $\mathrm{M}_{1}$ & I \\
R116W & Sweden & 246 or 248 & 194 or 196 & 250 & $\mathrm{M}_{3}$ & V \\
& & 240 or 246 & 194 & 248 or 254 & $\mathrm{M}_{5}$ & VI \\
& & 246 & 188 or 194 & 248 or 250 & $\mathrm{M}_{2}$ or $\mathrm{M}_{3}$ & III or V or VII \\
& & 240 & 194 & 250 & $\mathrm{M}_{2}$ & VIII $^{\mathrm{b}}$ \\
& & 246 & 196 & 252 & $\mathrm{M}_{2}$ & IX \\
\hline
\end{tabular}

${ }^{\text {a }}$ SNP 6 - SNP 7 - SNP 8 - SNP 9-SNP 10 - SNP 11 - SNP 12 combined in one highly informative marker $\left(\mathrm{M}_{i}\right)$.

${ }^{\mathrm{b}}$ It may be similar to haplotype III or V, but it is also conceivable that it is a new haplotype VII

${ }^{\mathrm{c}}$ This haplotype might have originated from haplotype III by a recombination between D11S939 and HMBS

(Fig. 1).

tected (Table 1). Seven of them have previously been reported, while the other five were new $[12,18]$. These findings were as expected as SNPs are believed to occur approximately once every 100 to 300 bases in the genome. Seven SNPs were regarded as most informative and easy to score $(*)$, and they were combined in one highly informative marker (Mi) for easier haplotype construction (Table 2).

Eighteen normal haplotypes were found in 31 healthy individuals from Norwegian AIP families, all different from the mutant haplotypes. In the 13 Swedish healthy individuals investigated 16 different normal haplotypes were found, including the haplotypes VI and VIII segre- gating with disease. The other mutant haplotypes were not detected in any normal haplotypes in our sample of healthy individuals.

All of the Norwegian families with the mutation W198X shared the same mutated haplotype segregating with disease, described as haplotype I (Table 2). In addition, this same haplotype I was also displayed in the five Swedish W198X families.

The mutation R116W was in contrast represented on three different haplotypes in the three Norwegian families investigated. A fourth haplotype (not described in Table 2) was discovered in one patient due to recombination between the HMBS gene and the 3' flanking mi- 
SNP 4 in intron 6, 4589del8

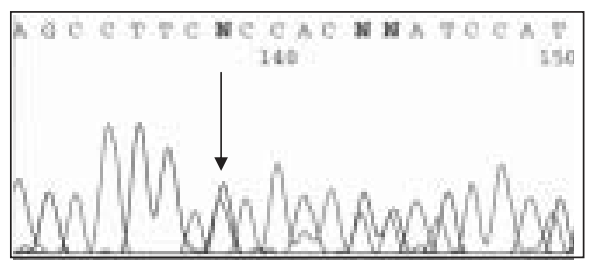

SNP 5 in intron 8, 5099 T/G

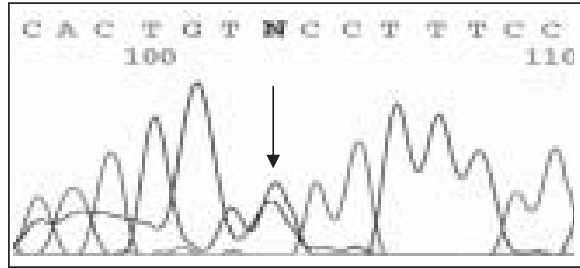

SNP 6 in intron 9, $5481 \mathbf{C} / \mathbf{T}$

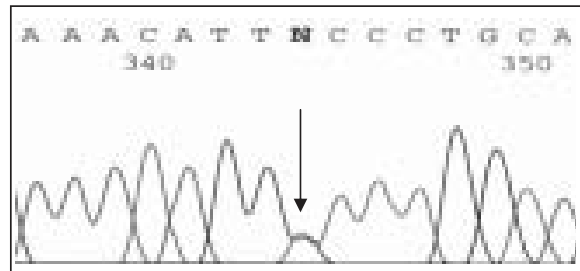

SNP 7 in intron 9, $6324 \mathbf{C} / \mathbf{T}$
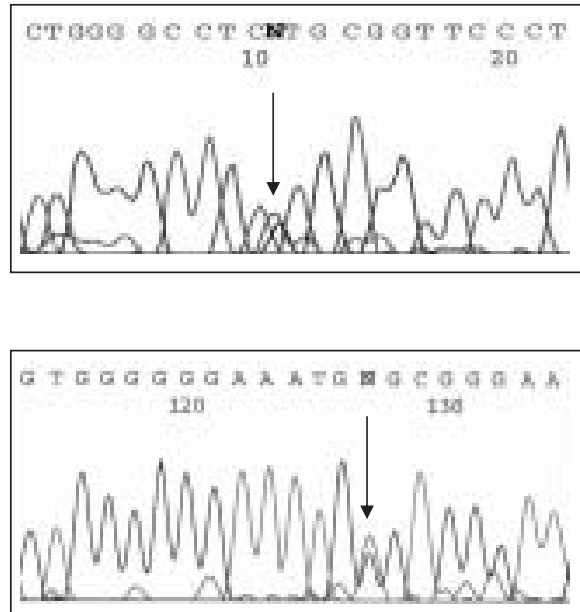

SNP 11 in intron 13,7787 G/A

Fig. 1. Sequencing results showing the five new SNPs found in AIP patients by F-REF-SSCP analysis.

crosatellite marker D11S4104 (Fig. 1). The three haplotypes linked to R116W in Norwegian AIP families are described as haplotypes II, III and IV (Table 2).

In the five Swedish families with R116W, four or five different haplotypes were present. These are described as haplotypes V, VI, III or V or VII, VIII and IX, all except haplotype III were different from the three found in Norway (Table 2).

Four different disease-related AIP mutations were found in the 20 Norwegian families presumed to have AIP based on clinical observations and biochemical analysis. R116W (CGG $\rightarrow$ TGG) and W198X $(\mathrm{TGG} \rightarrow \mathrm{TAG}$ ) were found in respectively five and nine families, while four families did not display any mutation. Two families were demonstrated to have their own specific mutation. These two point mutations have not been described before, and predict the amino acid substitutions V215E (GTG $\rightarrow$ GAG) and L238P $(\mathrm{CTG} \rightarrow \mathrm{CCG})$. 


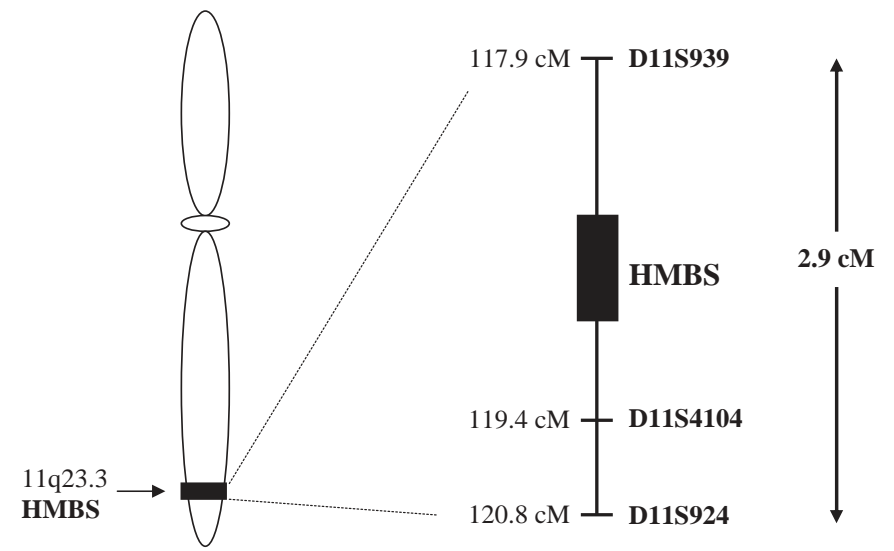

$1 \mathrm{cM} \approx 1000 \mathrm{~kb}$

Fig. 2. The location of the three microsatellite markers flanking the HMBS gene in the chromosomal region 11q23.1-q23.3.

\section{Discussion}

Except from the report of the G111R mutation [4] and R173W [21], haplotype analysis has not been applied to the HMBS locus before to study the history of mutations. Since R116W was reported to occur in very different populations, and our initial studies suggested that it segregated with more than one haplotype, we wanted to extend our study to include all the available Norwegian and Swedish AIP families.

The informative markers applied revealed a high degree of haplotype heterogeneity in the HMBS locus. One single haplotype (haplotype I) was linked to W198X in all cases in both countries, demonstrating that $\mathrm{W} 198 \mathrm{X}$ is a founder mutation. This has also previously been suggested from pedigree analysis of Swedish families [13]. The prevalence of this mutation is highest in Lappland in northern Sweden, pointing to this as the first founding population. From northern Norway the geographical distance to this founder population of W198X is also very short.

On the contrary, each except perhaps one of the R116W mutations segregates with its own specific haplotype in both Norway and Sweden (Table 2B). These findings exclude that the wide distribution, and relatively high frequency, is due to a founder mechanism. The mechanism of recurrent mutations is far more likely for the R116W mutation.

An explanation to R116W being a recurrent mutation could be a $\mathrm{CG} \rightarrow \mathrm{TG}$ substitution [17], since the general probability for a mutation to arise independently in several different individuals is low. In vertebrate genomes $90 \%$ of the methylated cytosine occur within the dinucleotide $\mathrm{CpG}$, and it has been calculated that this methylated cytosine is between 10-20 times more mutable than unmodified cytosine [1]. This result in an under-representation of the dinucleotides $\mathrm{CpG}$ in the vertebrate genome, described as "CpG suppression". It has also been demonstrated that a substantial portion of mutations causing human genetic diseases occur within $\mathrm{CpG}$ dinucleotides, and are the result of $\mathrm{C} \rightarrow \mathrm{T}$ or $\mathrm{G} \rightarrow \mathrm{A}$ transitions [3]. Thus reports of this mutation in other populations, very distant from northern Scandinavia, were as expected.

The high heterogeneity of the intragenic SNPs in the HMBS locus, detected with F-REF-SSCP [2], easily portrayed the diversity of haplotypes allowing the recognition of recurrent mutations. Since few AIP patients within each family at this point were available, some of our flanking microsatellites were uninformative. In most of these cases intragenic SNPs made it possible to recognize the different haplotypes for R116W. The F-REF-SSCP method was specifically designed to be optimal for screening exon 3-15 in the HMBS gene for SNPs in a simple and automated way.

We found four different mutations in the HMBS gene, in Norwegian families presumed to have AIP. Three were missense mutations resulting in radical shifts changing amino acids with basic side chains to aromatic, nonpolar to polar and to structural amino acids like proline. They affect highly conserved residues in HMBS [22], and thus likely to disrupt gene function [6]. One mutation was a nonsense mutation resulting in an inactive protein [6].

In conclusion, the AIP mutation $\mathrm{R} 116 \mathrm{~W}$ is a recurrent mutation explained by the high mutability of $\mathrm{CpG}$ dinucleotides. Thus, it is likely that the haplotype heterogeneity so far noted will be extended by haplo- 
type studies in other populations demonstrated to have R116W, e.g. Finland, The Netherlands, France, Spain and South Africa. In contrast, W198X originates from a common gene source, both from molecular genetic and genealogical analyses, and is a founder mutation.

\section{Acknowledgements}

A special thanks to Niels Erik Petersen and the staff at the Department of Clinical Biochemistry and Clinical Genetics, Odense University Hospital, for the technical assistance with establishing DGGE.

\section{References}

[1] C.D. Bottema, R.P. Ketterling and E. Vielhaber et al., The pattern of spontaneous germ-line mutation: relative rates of mutation at or near $\mathrm{CpG}$ dinucleotides in the factor IX gene, Hum. Genet. 91 (1993), 496-503.

[2] O. Bruland, K. Tjensvoll and P.M. Knappskog, Fluorescent REF-SSCP. In manuscript.

[3] D.N. Cooper and H. Youssoufian, The $\mathrm{CpG}$ dinucleotide and human genetic disease, Hum. Genet. 78 (1988), 151-155.

[4] A. De Siervi, M.V. Rossetti and V.E. Parera et al., Identification and characterization of hydroxymethylbilane synthase mutations causing acute intermittent porphyria: evidence for an ancestral founder of the common G111R mutation, Am. J. Med. Genet. 86 (1999), 366-375.

[5] G.H. Elder, Molecular genetics of disorders of haem biosynthesis, J. Clin. Pathol. 46 (1993), 977-981.

[6] Y. Floderus, P.M. Shoolingin-Jordan and P. Harper, Acute intermittent porphyria in Sweden. Molecular, functional and clinical consequences of some new mutations found in the porphobilinogen deaminase gene, Clin Genet. 62 (2002), 288297.

[7] B. Grandchamp, C. Picat and F. De Rooij et al., A point mutation $\mathrm{G}-\mathrm{A}$ in exon 12 of the porphobilinogen deaminase gene results in exon skipping and is responsible for acute intermittent porphyria, Nucleic Acids Res. 17 (1989), 66376649 .

[8] B. Grandchamp, C. Picat and R. Kauppinen et al., Molecular analysis of acute intermittent porphyria in a Finnish family with normal erythrocyte porphobilinogen deaminase, Eur. J. Clin. Invest. 19 (1989), 415-418.

[9] X.F. Gu, F. De Rooij and J.S. Lee et al., High prevalence of a point mutation in the porphobilinogen deaminase gene in
Dutch patients with acute intermittent porphyria, Hum. Genet. 91 (1993), 128-130.

[10] R. Kauppinen, S. Mustajoki, H. Pihlaja, L. Peltonen and P. Mustajoki, Acute intermittent porphyria in Finland: $19 \mathrm{mu}-$ tations in the porphobilinogen deaminase gene, Hum. Mol. Genet. 4 (1995), 215-222.

[11] M. Krawczak and D.N. Cooper, The Human Gene Mutation Database (HGMD), Cardiff. Trends. Genet. 13 (1997), 121122.

12] C.W. Lam, P.M. Poon and S.F. Tong et al., Novel mutation and polymorphisms of the HMBS gene detected by denaturing HPLC, Clin. Chem. 47 (2001), 343-346.

[13] J.S. Lee and M. Anvret, Identification of the most common mutation within the porphobilinogen deaminase gene in Swedish patients with acute intermittent porphyria, Proc. Natl. Acad. Sci USA 88 (1991), 10912-10915.

[14] J.S. Lee, B. Granchamp and M. Anvret, A point mutation of the human porphobilinogen deaminase gene in a Swedish family with acute intermittent porphyria, Am. J. Hum. Genet. Suppl. 47 (1990), A162.

[15] H. Nissen, N.E. Petersen and S. Mustajoki et al., Diagnostic strategy, genetic diagnosis and identification of new mutations in intermittent porphyria by denaturing gradient gel electrophoresis, Hum. Mutat. 9 (1997), 122-130.

[16] P.M. Ong, W.G. Lanyon and G. Graham et al., Acute intermittent porphyria: the in vitro expression of mutant hydroxymethylbilane synthase, Mol. Cell. Probes. 11 (1997), 293296.

[17] P.M. Ong, W.G. Lanyon and R.J. Hift et al., Detection of four mutations in six unrelated South African patients with acute intermittent porphyria, Mol. Cell. Probes. 10 (1996), 57-61.

[18] A.M. Robreau-Fraolini, H. Puy and C. Aquaron et al., Porphobilinogen deaminase gene in African and Afro-Caribbean ethnic groups: mutations causing acute intermittent porphyria and specific intragenic polymorphisms, Hum. Genet. 107 (2000), 150-159.

[19] E. Sagen, A. Laegreid and M. Anvret et al., Genetic carrier detection in Norwegian families with acute intermittent porphyria, Scand. J. Clin. Lab. Invest. 53 (1993), 687-691.

[20] C. Solis, I. Lopez-Echaniz, D. Sefarty-Graneda, K.H. Astrin and R.J. Desnick, Identification and expression of mutations in the hydroxymethylbilane synthase gene causing acute intermittent porphyria (AIP), Mol. Med. 5 (1999), 664-671.

[21] S.D. Whatley, A.G. Roberts and G.H. Elder, De-novo mutation and sporadic presentation of acute intermittent porphyria, Lancet. 346 (1995), 1007-1008.

[22] S. Wood, R. Lambert and P. Jordan, Molecular basis of acute intermittent porphyria, Mol. Med. Today. 1 (1995), 232-239.

[23] H.W. Yoo, C.A. Warner, C.H. Chen and R.J. Desnick, Hydroxymethylbilane synthase: complete genomic sequence and amplifiable polymorphisms in the human gene, Genomics. 15 (1993), 21-29. 


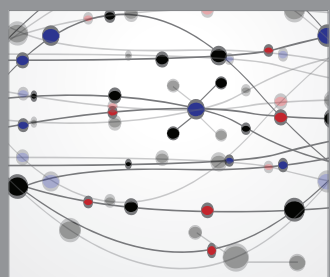

The Scientific World Journal
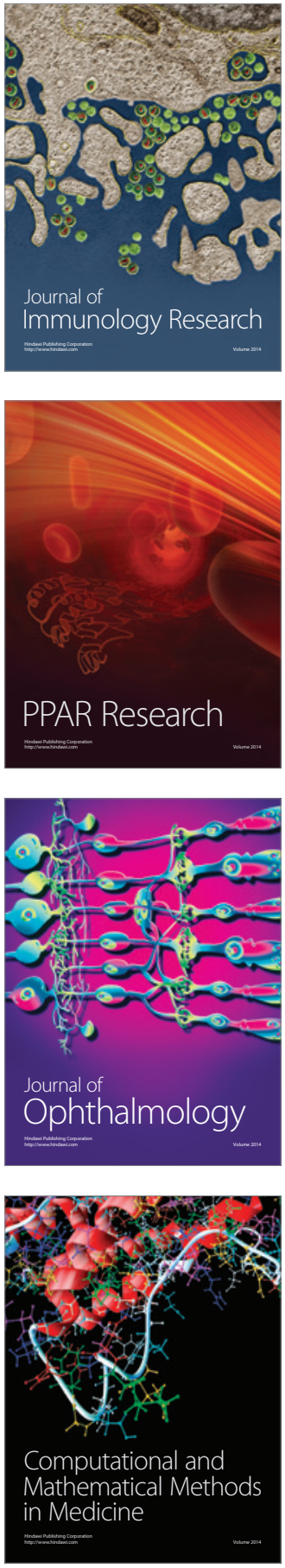

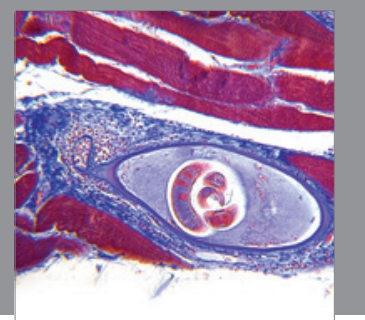

Gastroenterology

Research and Practice
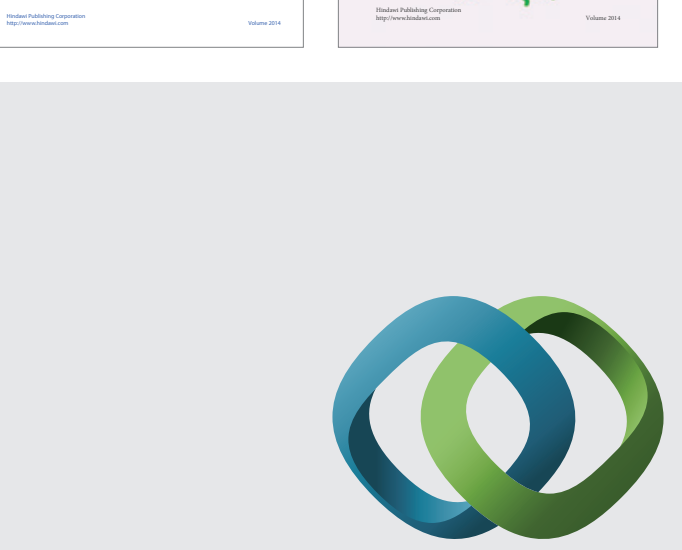

\section{Hindawi}

Submit your manuscripts at

http://www.hindawi.com
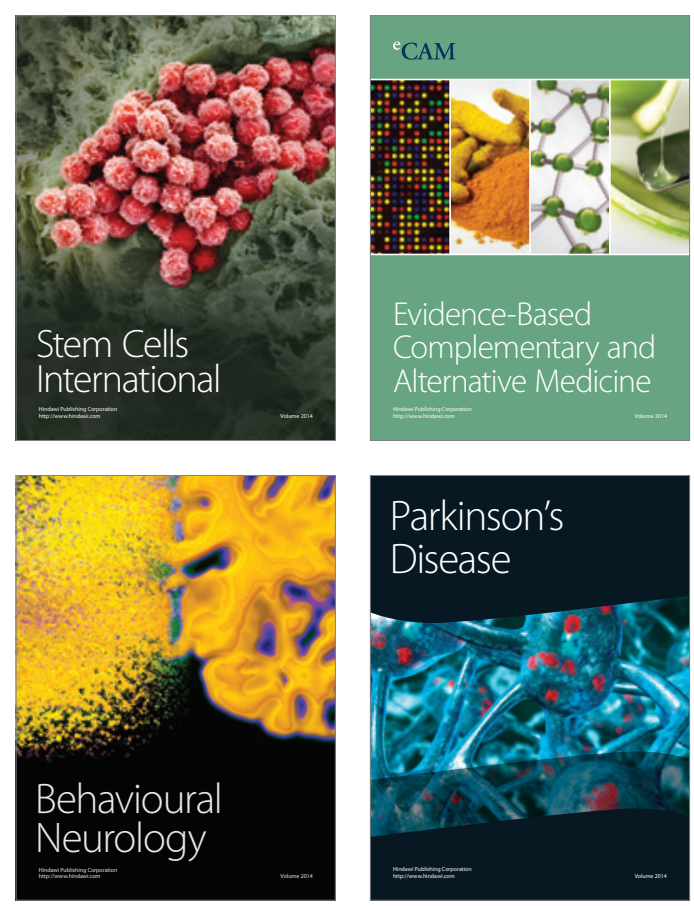

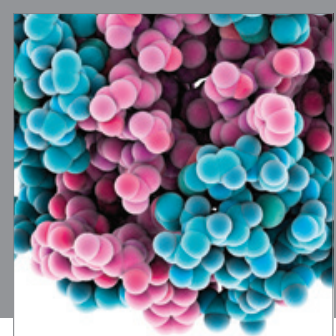

Journal of
Diabetes Research

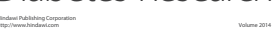

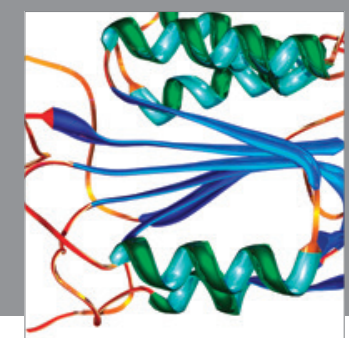

Disease Markers
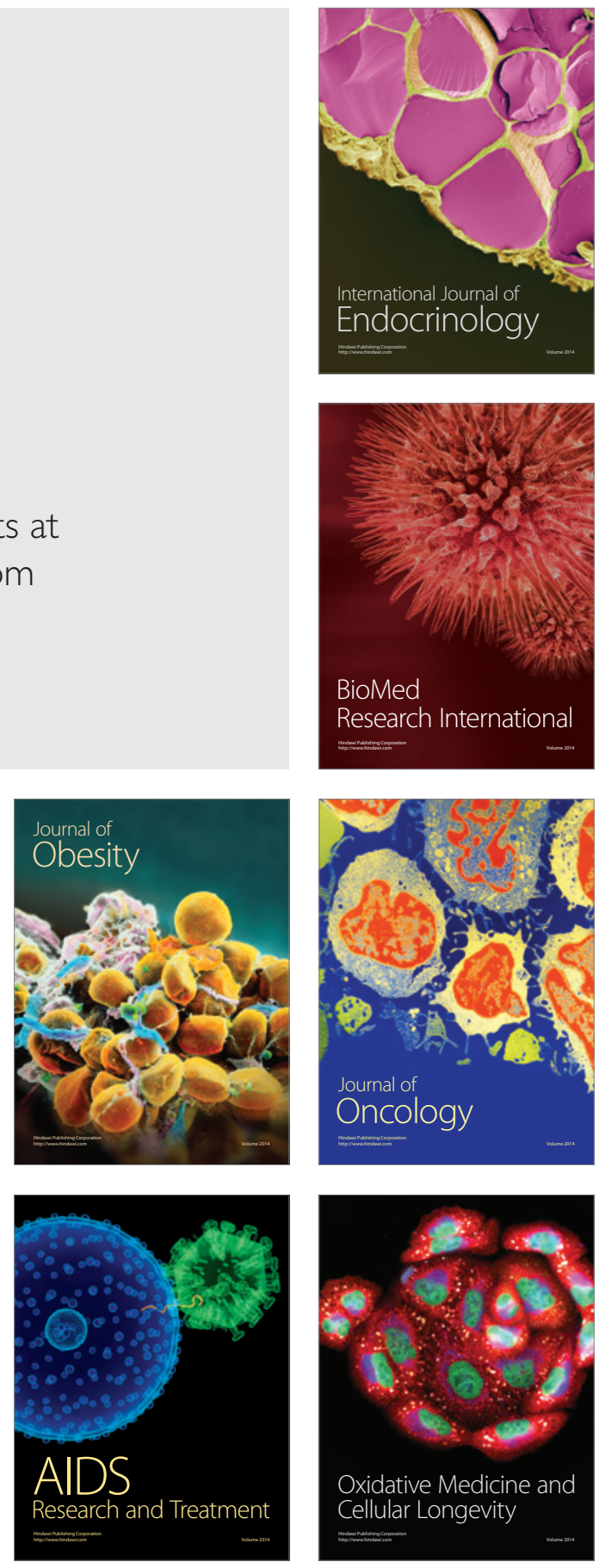